\title{
The voices of parents and children in foster care
}

Journal of Social Work $0(0) 1-19$

(C) The Author(s) 2020

Article reuse guidelines: sagepub.com/journals-permissions DOI: 10.1 I77//4680173209586/8 journals.sagepub.com/home/jsw

(SAGE

\section{Aida Urrea Monclús}

Autonomous University of Barcelona, Barcelona, Spain

\section{Ainoa Mateos Inchaurrondo}

University of Barcelona, Barcelona, Spain

\section{Laura Fernández-Rodrigo and M Àngels Balsells Bailón}

University of Lleida, Lleida, Spain

\begin{abstract}
- Summary: This article presents the results of a qualitative study whose objective was to collect information on the perceptions of changes in parents and their children who are in the Spanish foster care system after completing a positive parenting programme. - Findings: The participants in the focus groups included 66 parents and 57 children. Triangulation of the voices of all protagonists identified findings that suggest the need for changes regarding understanding foster care measures and the process of family resilience; the quality and content of visits and contact between parents and children; and the role of professionals involved in the case.

- Applications: The findings indicate the efficacy of the intervention proposed in the 'Walking family' programme with the direct and active involvement of children as they become a driver of change for the parents. However, when this does not occur, professionals must work from a critical approach and should provide a realistic view of the family to children.
\end{abstract}

\section{Keywords}

Social work, foster care, parenting, child and family welfare, evidence based practice, participation

\footnotetext{
Corresponding author:

Aida Urrea Monclús, Faculty of Science Education, Department of Theory of Education and Social Pedagogy, Autonomous University of Barcelona, G6 Building, UAB Campus, 08193 Cerdanyola del Vallès, Barcelona, Spain.

Email: aida.urrea@uab.cat
} 


\section{Introduction}

In situations of helplessness caused by maltreatment or neglect, the protection of children and adolescents consists of temporarily separating them from their biological family. Regardless of whether kinship foster care or residential care measures are adopted and considering that the return home of the child aligns with the best interests of the child, working with the biological family is necessary to ensure this return. Although, without forgetting that sometimes this option will be harmful and alternatives should be sought. These decisions of separation and reunification are of special relevance for children due to the short- and long-term influences on their lives (Farmer, 2014); furthermore, these decisions have a strong impact on the life of the family.

In Spain, according to the latest official data on the protection of children and adolescents (Ministerio de Sanidad Consumo y Bienestar Social, 2018), at the end of 2017, there were a total of 47,493 open records of children in protective care. The most frequent reason that children and young people are entered into care is negligence which represents $52 \%$ of the total cases, followed by, in this order, emotional abuse $(26 \%)$, physical abuse $(17 \%)$ and sexual abuse $(5 \%)$. Included amongst these cases are children and adolescents who are admitted to care for behavioural or emotional reasons.

With regard to care settings, in Spain 17,527 children were placed in residential care $(48 \%)$ and 19,004 with foster families $(52 \%)$. Kinship foster care predominates, with 12,748 foster children placed with relatives (representing 67\%) versus 6256 with non-relatives (33\%) (Ministerio de Sanidad Consumo y Bienestar Social, 2018). This predominance of kinship foster care can be justified by the principles and values of Spanish culture that strongly regards family connections.

With regard to residential care, the Spanish Child Protection System also has particularities. Stays in residential care tend to be prolonged, which represents a challenge to protection systems. López and del Valle (2015) note that the profile of children who spend the longest time in residential care is between 9 and 12 years old, who present behavioural and/or emotional difficulties and whose biological families show psychosocial problems. Another challenge of residential care in Spain is preparing foster children for their transition to adulthood. As indicated by Cuenca et al. (2018), many of these young people use their biological family as their main asylum once they reach the age of majority, which is negatively viewed by professionals who reject the suitability of the family.

Finally, a major challenge for childcare services is to increase the rate of family reunification. In Spain, this rate barely reaches $20 \%$ for children who have been in foster care, which means that more than $80 \%$ do not return to their biological family before reaching the age of majority (Ministerio de Sanidad Consumo y Bienestar Social, 2018). Another challenge is to improve the quality and number of care facilities for children and adolescents. Poor outcomes are being observed because children in the protection system are not receiving enough professional attention (Hansen \& Ainsworth, 2013; Turcotte \& Hélie, 2012) 


\section{Foster care measures}

The early foster care measures are characterised by critical periods of family adaptation. Although interventions are justified and carried out with the objective of protecting children and guaranteeing their maximum welfare, separation can be a traumatic event for the family as a whole and involves the beginning of an intense, emotional process.

Authors such as Farmer and Wijedasa (2013) note the importance of immediately working with a family from the moment at which family separation is proposed to collaborate with the family in the joint development of a plan of care.

The scientific literature has emphasised how the attitude of families (parents and children) regarding protective measures is key to advancing through processes of foster care and reunification. The research of Ellingsen et al. (2011) indicates the relevance of understanding family difficulties (insight) and the importance of parents being aware of the situation and understanding the reasons leading to the separation as an essential part of embracing an attitude towards change.

In the case of children and adolescents, an understanding of the reasons for foster care measures is often very limited. The adjustment of children to the measures adopted can be influenced by a lack of information and a lack of involvement in the process (Potgieter \& Hoosain, 2018), suggesting that policies encouraging children's attendance at dependency hearings are viewed positively and not harmful to children.

Nybell (2013) and Goodyer (2014) report that children enter foster care without knowing the reasons and without having enough information about what measures will be taken and what changes will occur in their lives. In Spain, this same reality of disinformation and lack of consultation regarding where the children will go leads to emotional difficulties in understanding the situation the children are experiencing (Mateos et al., 2017).

Attitude towards measures is also related to the family's degree of commitment. Lietz and Strength (2011) indicate that willingness and commitment to change and the unquestionable desire of the family to be reunited are the necessary variables in a process of family reunification. However, families cannot complete this process alone. Parents need support and opportunities that allow change and that, importantly, they take into account the child's best interest (Wilkins \& Farmer, 2015). Research has shown that parental involvement from the moment the case is being evaluated, that is, before separation, is a strategy that increases parents' commitment and ability to change (Balsells et al., 2019). For this, practitioners cannot prejudge parents and should listen and take into account their wishes (Benbenishty et al., 2015).

Finally, acceptance of the protective measures has been identified as necessary to advance through the process and requires time for each of those involved. Llosada-Gistau et al. (2017) explain that children in foster care must adapt to a new home, school, friendships and leisure spaces. Furthermore, they not only have to face the loss of cohabitation with their biological family but also face the loss of 
close relatives or pets, their space, their routines, their privacy and even their material goods, such as toys and clothing. In addition, they must address the stigma of being a protected child (Murphy \& Jenkinson, 2012).

The emotional state, in which families find themselves at the moment that foster measures begin, blocks the reception of information and hinders engagement and involvement in the process. For this reason, their understanding of what is happening, as well as their collaboration with professionals, can be influenced. Lietz and Strength (2011), in their proposal for a process of resilience in family reunification, call this the 'survival' stage, stating that during this period, families only intend to 'survive day to day' until they can accept and adapt.

\section{Visits and contact}

Both Thomas et al. (2005) and Ellingsen et al. (2011) state that a real, permanent and secure bond between the biological family and their children in foster care exerts a positive effect on the recovery of the family unit. Scheduled visits and contact among family members ensures that these links are maintained and improved, given that the quality and quantity of visits and contact between parents and their children directly influences the family reunification process (Kiraly \& Humphreys, 2013). The research by Goemans et al. (2016) noted that children who had contact with their parents were 13 times more likely to be reunited. According to the studies by León and Palacios (2004), interactions are necessary events for the process, as they help maintain the link between the parties involved. In the study by Thomas et al. (2005), children's perception of the affection they receive from their parents is highlighted. The existence of an affectionate bond and the fact that they feel loved by their parents' increases the probability of family reunification. This finding aligns with the data presented by Balsells et al. (2014); they consider the affectionate needs of children to be an important component to work on to ensure the positive development of visits. In turn, recent studies (Fuentes et al., 2018) present the positive view that both social service professionals and foster families have regarding visits and contact between children and their biological family, indicating that visits maintain the affectionate bond between a child and the biological family, give meaning to the child's identity and allow the child to understand his or her personal and family history. Potgieter and Hoosain (2018) propose the following significant elements for maintaining the family's commitment to visits and contact: provide families with resources to perform recreational activities during visits, offer communication alternatives such as WhatsApp and maintain respect and consistency with the visit and contact rules.

\section{Positive parenting programmes}

To facilitate change after the separation of the biological parents and their children, improving the parental skills of those involved is important (Delfabbro 
et al., 2013). A positive parenting framework helps to analyse situations of abuse, neglect and abandonment from a positive perspective centred on the abilities that these families have to take care of their children and to focus on socio-educational interventions that enable the acquisition of parenting skills (López \& Del Valle , 2015; Rodrigo, 2010; Rodrigo et al., 2015). This framework enables the development of new professional practices with a scientific foundation that includes an ecological, inclusive and participatory approach (Balsells et al., 2019). Along this line, several authors support the implementation of socio-educational programmes to teach parenting skills (Arranz et al., 2019) and provide specific educational needs for each stage of the reunification process (Balsells et al., 2018).

The attainment and improvement of parenting skills ensures the welfare of the child in a family but involves specific work. This work should include both parents and children because they are active agents in the possibility of family reunification. For this purpose, the socio-educational programme 'Walking family (Caminar en familia)' was developed (Balsells et al., 2015), whose purpose is improving specific parenting skills in a process of fostering and reunification. It is structured in five modules of three sessions each. The implementation of each module is adjusted to the different moments of the reunification process. For this reason, the first package (M1-M2) is specific to fostering and the second (M3-M4-M5) is given in the moments near reunification. Weekly implementation is recommended and includes three types of activities: (1) group activities for parents; (2) in parallel, activities for sons and daughters; and (3) family activities (parents and children together). The latter are carried out during visits or contact and consist of small tasks to consolidate the contents of the sessions that they undertake separately. The professionals of the child protection system are in charge of leading and coordinating the different services involved in its implementation: specialised childhood teams, residential centres, teams who work with foster families, social workers who work with birth families, etc.

This programme sets itself apart from other positive parenting programmes. On the one hand, it belongs to third-generation positive parenting education that, in addition to taking the context into account, incorporates dynamic and participatory elements that include the whole family. On the other hand, it is an evidence-based programme whose definition indicates that it is based on theory, with well-structured and described contents with evidence of positive outcomes as well as defined factors that influence its implementation (Rodrigo, 2016). Finally, it is specific to working with the typical rivalries during foster care and in the first moments of family reunification. Given the evidence in the scientific literature, several questions arise: can parenting programmes improve the perception of parents and children regarding protective measures? Is the 'Walking family' programme effective in terms of perceived changes in attitudes towards the protection system, foster care measures and the professionals? Is there perceived improvement in the quality of visits and contact? 
Table I. Characteristics of the parents participating in the study.

\begin{tabular}{lll}
\hline Characteristics & Parents $(N=66)$ & Percentage \\
\hline Figure participating in the programme & & \\
Mother & 30 & $45.5 \%$ \\
Father & 5 & $7.6 \%$ \\
Both & 18 & $27.3 \%$ \\
Other & 1 & $1.5 \%$ \\
Non response/don't know & 12 & $18.2 \%$ \\
Mean age & 39.9 years old & \\
\hline
\end{tabular}

\section{Methodology}

The study aims to examine the perceptions of changes of foster care measures and of the quality of visits and contact of parents and their children who are in foster care and who have participated in the first package of the 'Walking family' programme. M1 addresses the child protection measure and is aimed at families who are at the beginning moments of foster care, whether in residential or family care and where parents have already begun a process of change. M2 deals with visits and contacts and aims to help families to be able to make quality visits and maintain contacts during foster care.

The design of the research is qualitative with a comprehensive descriptive purpose. This methodology allows us to gather subjective views of the protagonists, making it possible to accurately sum up their experiences, feelings and opinions by collecting them in their own words. This facilitates discovering the meanings that these families attribute to their experiences in the foster care system after participating in the 'Walking family' programme.

\section{Participants}

The 'Walking family' programme was implemented in different regions of Spain. There were 107 families who carried out modules 1 and 2, a total of 135 parents and 115 children. Of these, $49.2 \%$ participated in the qualitative study presented (Tables 1 and 2).

\section{Data collection instruments}

Information was collected through focus groups. Groups were held with parents whose children were in foster care and with the children of those parents. For the development of the focus groups, three documents were prepared: (a) an identification card to collect basic data regarding the participants; (b) a script of questions for organising the focus groups; and (c) a summary record where the researchers noted relevant aspects that occurred during the meeting, such as date, place, moderator, group climate, incidents and contributions to highlight. 
Table 2. Characteristics of the children participating in the study.

\begin{tabular}{lll}
\hline Characteristics & Children $(N=57)$ & Percentage \\
\hline Sex & 26 & \\
$\quad$ Female & 7 & $45.6 \%$ \\
$\quad$ Male & 4 & $47.4 \%$ \\
$\quad$ Non response/don't know & & $7.0 \%$ \\
Age & 10 & \\
5-8 years & 20 & $17.5 \%$ \\
$9-12$ years & 17 & $35.1 \%$ \\
I3-16 years & 3 & $29.8 \%$ \\
Older than I7 years & 7 & $5.3 \%$ \\
Non response/don't know & & $12.3 \%$ \\
Protective measure & 2 & $3.5 \%$ \\
Kinship foster care (KC) & 2 & $3.5 \%$ \\
Out-of-home foster care (FC) & 29 & $50.9 \%$ \\
Residential foster care (RC) & 24 & $42.1 \%$ \\
Other/non response/don't know & & \\
\hline
\end{tabular}

The question scripts for the respective focus groups were developed based on a review of the scientific literature and based on the objectives of the 'Walking family' programme. They included questions regarding the foster care measures adopted and visits and contact between parents and their children (Table 3). The same questions were written in different ways to adapt to the understanding of parents and children. Additionally, in the cases of the youngest children, the meaning of the questions was carefully explained to them.

\section{Procedure and data analysis}

A total of 24 focus groups were held: 12 groups with parents (G_Parents) and 12 groups with children (G_Children). They took place between March 2017 and February 2018. The focus groups were audio-recorded, with prior informed consent and transcribed verbatim to ensure the accuracy of the information.

Content analysis was the fundamental methodology for analysing the transcripts and was carried out as described below (Gibbs, 2012):

a. Development of a system of categories. First, a system of textual categories was developed through the coding of a few transcripts according to the information provided by the participants. Second, the system of categories was reviewed and modified considering the conceptual contributions of the literature. Four researchers participated in the development of the system.

b. Coding. Once the category system was developed (Table 4), each focus group was coded independently by two researchers. Elements of disagreement were searched for, and negative data were also coded. Subsequently, the discrepancies 
Journal of Social Work 0(0)

Table 3. Question script for the focus groups.

Children Parents

- The first module, the one about the measure, did it make you change your opinion about foster care/the centre in which you were living? In what sense? At that time, did it help you to know and better understand why your parents could not take care of you?

- Regarding module 2, visits and contact, do you think it helped improve the visits with your parents? Did these sessions help you to manage your emotions better?

- Overall, would you say that these activities have helped improve the visits and contact with your parents? And in your foster care situation? In what ways has there been improvement, both for

- The first module, the one about the measure, did it help you to better understand foster care? At that time, did it help you better understand why your child was away from home and in the place where he/she was?

- Regarding module 2, visits and contact, how do you think it helped improve the visits with your children?

- Overall, how has participating in 'Walking family' helped you in the reunification process?

you and your parents? What changes have you made? What things from the programme have helped you most in this improvement?

Table 4. System of categories of analysis.

\begin{tabular}{lll}
\hline Domain & Category & Definition \\
\hline Measures & $\begin{array}{c}\text { Understanding the } \\
\text { measures } \\
\text { adopted } \\
\text { Acceptance of the } \\
\text { problem } \\
\text { Differential roles }\end{array}$ & $\begin{array}{c}\text { Characteristics of the measures and the reasons } \\
\text { for separation }\end{array}$ \\
& $\begin{array}{c}\text { Description of difficulties in meeting the needs of } \\
\text { children } \\
\text { Functions of the agents involved in the measure } \\
\text { (professionals, co-facilitators, facilitators and }\end{array}$ \\
& $\begin{array}{c}\text { other support people) or of the system } \\
\text { Involvement and } \\
\text { planning of visits }\end{array}$ & $\begin{array}{c}\text { Interest in planning visits: what to do, how and } \\
\text { when }\end{array}$ \\
& Communication in & Communication skills and content developed in \\
& visits & the context of visits
\end{tabular}

were analysed, and agreement was reached. Support for this process was provided through Atlas.ti software for qualitative data analysis.

Following this structured process during the analysis of the data revealed elements that ensured the credibility, transfer and reliability of the results of this 
research. Credibility was guaranteed through validation by experts in the field of the system of categories and the detailed description of each of the domains and categories of analysis. Each of the researchers encoded the text the same way, all with the same understanding of both the category and the discourses of the participants. Transference was ensured from the sample that represented the subjects participating in the 'Walking family' programme. Thus, $48.8 \%$ of parents and $49.6 \%$ of children participating in the programme attended the various focus groups. The reliability and validity of the study was ensured through monitoring mechanisms of the research team itself and validation by judges of the data analysis system. This allowed researchers to adequately identify the issues that underlie the discussions in groups of parents and their children. The triangulation of information from different groups of participants allowed learning the different angles and perspectives of the same reality in the same family experience.

\section{Ethics considerations}

To comply with ethics considerations, an informed consent document was prepared for the participants, explaining the aim of the research, the scientific purpose, their rights as participants and the confidential treatment of the data collected. At the beginning of the focus groups, the participants were encouraged to ask any questions to corroborate their understanding and willingness to participate. In the case of children, authorisation and consent were requested from their parents or the public administration that had legal guardianship at the time of the study.

\section{Findings}

The results presented here reflect the perceptions of both parents and their children regarding the changes produced, following the implementation of the 'Walking family' programme, on elements that have to do with foster care measures and visits and contact.

\section{Foster care measures}

The moment of separation and/or entry of a child into the foster care system is traumatic for both parents and children and involves a period of adaptation to the new situation. The results indicate how families can have different levels of understanding of the measures depending on the process they are developing and the support offered. Thus, the results show that even when the programme was carried out, there are participants (both parents and children) who have a low level of understanding of the measures and are angry at the protection system.

I don't want to be here and being here has made me angry a lot. In my house, I was angry but did not react the same way I do now with educators. (G_Children_6) 
However, there are families who have managed to understand the situation in which they find themselves and recognise the measure of having their children fostered as formal support.

Well, at first you feel they are the bad guys in the movie [...] because every family has its problems [...] and then you understand and see your mistakes. (G_Parents_4)

However, some families have adapted to the situation, recounting the measure and not putting effort into making changes to have their children return home.

Another factor that stands out in a foster care process is the acceptance of the reasons that led to family separation. Just as understanding the measures, acceptance of the problem requires a process and several phases before achieving acceptance. The results indicate that families who are in very early stages of the process justify their parental role and/or blame their children for the problem and feel it is the children's responsibility to change. Furthermore, they comply with the case plan out of obligation, reject the support of the programme and maintain a hostile attitude towards it.

I just want to get through this ordeal. No, I did not like the course, and it did not serve me well. The only thing I'm missing are the videos saying that I also lost my son and people... (G_Parents_10)

At the first centre, they told me that my mother had a mental problem, but that is a lie. (G_Children_6)

Nonetheless, there are families that have managed to pass from this phase of anger to a phase of acceptance regarding the reason that led them to the current situation. This acceptance subsequently allows them to receive formal support and to make changes that result in reunification. The participants who are in this more advanced phase agree that the programme has allowed them to be aware of the needs of their children, to assess the changes and adjustments achieved, to identify parenting skills and to be grateful for the help received.

In the first module, I realised what I was doing when I drank, why I was not attending to my children. Now drinking is the last thing I have on my mind. (G_Parents_9)

My mother has her reasons for not taking care of me. Now I understand why everything happened, and I hope she doesn't do the same thing again. (G_Children_3)

As already mentioned, when a foster care process begins, there are various elements that both parents and children do not know. One of the elements is the agents who are involved in this process and their different roles. Ignorance of the people with whom the children will be spending most of their time and of the people who will be dealing with the parents, among others, is cause for anxiety, 
suspicion and distrust on the part of the families towards the protection system and towards the agents. The results of this study suggest that programme participants who are at a very early stage in the identification of the roles of the different agents assume a negative attitude towards the protection system. Some parents who are in this phase believe that the technicians plant obstacles to facilitate change, and children at this stage do not understand the protection measures or the role of the different agents and feel that they are victims of the situation.

Well, they take my son from me, and they have not let us say anything, and it is useless for us to present what our neighbours and friends say; what matters is only what they say. (G_Parents_11)

However, a more positive attitude is perceived towards the protection system and towards the formal support received by those participants who have advanced in their process and are in a phase of acceptance and growth. Both parents and children perceive, as a facilitating element, that they can rely on both formal and informal support and value the changes they have made in their lives.

The programme has helped identify what is happening, and we are willing to do anything so that they will come back. I've understood that I need help for certain things such as taking care of them, taking them to school, etc. (G_Parents_8)

\section{Visits and contact}

Visits and contact established between parents and their children are an important element in a foster care process. It is the moment of reuniting the family, of spending time together, of asking how they are, of explaining how their progress is going, of improving the quality of their relationships, etc. For this, it is necessary for the visits to be of high quality.

The results of the study show how parents who are not aware of the problem that led to separation and do not perceive the need for change believe that visits maintain the same dynamics as before carrying out the programme: superficial visits and without regard for the children needs and which are summarised in being in the same space and time. Others mention that the programme did not provide them with new knowledge, or they point out the difficulty of keeping up with the programme because of having fewer visits than required. The children of these parents say that their parents' bad attitude poses a barrier to improving the quality of the visits.

For me, what has changed is that I have not seen my father for three or four months because he is as stubborn as a mule.... (G_Children_6)

In contrast, there are parents who point out the help the programme has provided in relation to visits. They think that the programme has helped them learn how to 
plan their visits, to manage their visit time and to address the issues concerning their children. In addition, they feel that they demonstrate a more positive attitude during visits. The children who also perceive this improvement are aware of the changes made by their parents and detect a change in their own attitude.

They were another kind of visit. Of course, they helped you because if you choose a weekend, you have to have something planned or plan a day ahead of time or all of that with your daughter to know what you are going to do. (G_Parents_1)

Another noteworthy aspect found in the results is the improvement in communication between family members during visits. Some parents state that after the implementation of the programme, the relationship established between family members has improved because they can better detect the needs of their children, they know how to create mutual respect between them and their listening skills have improved. These improvements occurred because of actively engaging in the programme content and because of their own predisposition to change.

We listen to each other; we know how to anticipate their needs now because before we had our world, right? [....] This has helped the way we talk to them. (G_Parents_7)

The children corroborate this perception and point out that they now feel heard by their parents and value that their parents take more interest in them. They also report that their communication skills have improved after going through the programme, as they externalise and express their feelings better, and perceive that their parents have also improved in this regard.

We had two visits doing this, and yes, I notice it being better; we talked more, and we had more fun because in our visits, we used to be like this, with our arms crossed, in mode 'how are you?' and were a little bored. (G_Children_6)

In foster care situations where family members are temporarily separated, affection plays an important role. Both parents and children need to feel loved and feel that their family members have not abandoned them or replaced them. Affection is another noteworthy aspect, as well as involvement in and planning of visits and communication. The findings indicate that parents increased their affection towards their children and changed their affective style. The children corroborate this idea and, in addition, consider that greater trust has been established by both parties.

She didn't pay attention to me, didn't kiss me, didn't say nice things ... and now during visits, she gives me kisses, you know? I notice a change towards me...I think this programme has gone well...I will ask her about it later. (G_Children_10)

The results show that the programme helps improve the affectionate style and emotional expression of the different members of the family. However, if any 
family member does not come to terms with the measures and accept the problem, he or she does not have the capacity to make changes and improve their loving relationship with the rest of the members. This causes frustration with the other members because they are unable to channel their feelings to their unaccepting loved ones and prove how the immobility is negatively affecting their situation.

When the time is almost up, she starts crying, and of course, she makes me cry. I can't cheer her up, because I can't, because it makes me cry and it breaks my heart. I feel sad then... I cannot do anything. (G_Children_10)

Related to the foster care process and the previously mentioned content, the results indicate some elements that facilitate the process. On the one hand, parents note how the attitude of the professional in charge can facilitate or hinder the process of understanding the measures as well as the acceptance of the problem. On the other hand, children value the programme as a necessary support resource, both for them and for their parents, and point out the experimental activities as facilitating elements for understanding the measures.

A person who has a good attitude towards you and explains things better and all that, and you understand it. (G_Parents_1)

The results also indicate that the 'Walking family' programme and its group methodology facilitates acceptance of the measure. Participants in the programme note that sharing experiences with other families who are going through the same process makes them feel less alone in the situation and more focussed on a solution, creating a climate of mutual support among the participants.

You see that there are many families that have problems. There are times when you think that you are the only one who has problems... They stir up many feelings, you remember things...(G_Parents_3)

\section{Discussion and recommendations}

The separation of a child from his or her family due to mistreatment, abuse or neglect is often a traumatic and painful moment for all family members. The process of understanding the protective measures and acceptance of the problem is different for each family and depends on many factors. However, the proactive management of cases with adequate resources has been recognised by international literature (Thoburn et al., 2012) as a fundamental element to help families move forward. The findings of the study have identified certain progress in the perception of changes in families - parents and children - who have participated in the 'Walking family' programme. 
A first finding refers to the relationship between a family resilience process and the protective measure itself. Both an understanding of the measure and acceptance of the problem and of the differential roles must be observed from a diachronic perspective. From the discourses of the participants, the heterogeneity of the families is confirmed, and according to the proposal of Lietz and Strength (2011), different stages of a process of family resilience are confirmed. In this sense, the results have shown families in a survival phase characterised by a lack of understanding and a hostile attitude towards the programme and towards the resources offered to them. First, this parental resistance seen in the early stages would be a logical response to what has occurred. Second, families that have overcome this first phase of rejection and are in the programme adaptation or acceptance phases are more receptive to receiving formal support, accepting the reason for the separation and, therefore, are more open to participating in the programme and making improvements that result in reunification with their children. Finally, families who not only accept the help offered by the programme but value it show a more positive attitude towards formal and informal support and are capable of identifying the needs of their children, the changes produced in the family and the evolution of parenting skills.

According to this data, the implication for practice refers to maintaining heterogeneous groups as it becomes a proactive driver of change for all participants. On the one hand, families in more advanced stages, according to the theories of Osterling and Han (2011) and Thomas et al. (2005), reinforce self-confidence, recognising individual merit and that of the rest of the family members, adding a sense of identity to the family and helping to preserve family unity because the family strives to remain together. On the other hand, families that have not overcome these first moments of distrust of the system can use other families that have passed that phase as an example. Some authors note that people passing through situations of risk attribute positive value to receiving support from other people who are experiencing or who have experienced the same situation (Bernedo et al., 2014). For families who are in this process, feeling supported by others prevents feelings of solitude, frustration, incomprehension and isolation.

A second finding refers to the effectiveness of the programme in improving the quality of visits and contact. The scientific literature recognises the importance of visits in protection processes because visits help children to maintain attachment relationships with their biological family and contribute to their sense of identity and understanding of their personal and family history (Biehal, 2014; Fuentes et al., 2018).

The findings based on the stories of the participants indicate improvements in communication, planning, time management and visit content. These results confirm the conclusions of the review by Maltais et al. (2019). In their systematic review of the literature, they found that most effective interventions to promote changes in the parents of children in foster care are family interventions that are intended to modify interactions in the family or in the relationship between parents and children. The results suggest the efficacy of the intervention proposed in the 
'Walking family' programme, specifically dedicated to the interaction of parents and children in the context of visits, with the direct and active involvement of children, as they become a driver of change for the parents. The fact that the programme is directed to both parents and children multiplies its effect, and these effects can further influence the parenting skills of their parents.

The implication for practice in the framework of child protection suggests that the objective of improving parenting requires work:

a. Oriented both to children and parents adapting parent-child activities to the age, interests and needs of the children as well as providing feedback on the successes experienced in each encounter between parents and children (Landsman et al., 2014);

b. Oriented specifically to improve the quality of the parent-child relationship through work on specific skills (Balsells et al., 2018; Dakof et al., 2010); and

c. With an ecological and family-type perspective that promotes the quality of family functioning as a system through comprehensive, multi-domain and multi-context lasting interventions (Dakof et al., 2010; Rodrigo, 2016).

\section{Limitations of the study}

The use of focus groups in research on sensitive topics such as child protection included some limitations and challenges. On the one hand, families are reluctant to respond because they do not know if it will affect their intervention plan. To mitigate this effect, the leaders of the focus groups were researchers and not related with the protection system, a safe atmosphere was created and was explained to families that the information would not be passed on to the protection professionals. On the other hand, children are tired of explaining their story to different people, at the same time they find it difficult to express themselves orally. Despite the adaptations of the language of the text and the establishment of good communication at the beginning of the group, it is considered a limitation not having applied techniques that favour Multilanguage. It is considered appropriate to take it into account for future occasions.

\section{Conclusions}

For all the above, despite the stated benefit that supposes that the children are at an advanced stage of their process (in which they understand the causes of the problem and accept the measures), even when their parents are not yet at that moment, suggests proposing, in the face of future studies and interventions, the following question: what do we do when the child or adolescent is seeing that he/ she is making an effort to change, and yet his/her parents do not follow the same process of change?

This issue invites us to continue reflecting on the differences in the perception of change between parents and children. It opens new avenues for proposing 
interventions, bearing in mind the premise that the starting points of parents and children are not always the same. This is not necessarily a negative issue. As noted above, this difference sometimes means that the children promote change in their parents. On other occasions, when this does not occur, we must work from a critical approach. Family reunification is not always achieved. Faced with this fact, professionals should provide a realistic view of the family that invites the child or adolescent to assume their own life story and accompany them towards autonomy for adult life.

To conclude, the methodology used for this research has explicitly sought the perception of children about their parents' changes. This has revealed a unique view of the child protection system and new knowledge about it based on the voice of children. As a future line of research, the voice of children should be considered and promoted in research on children and in interventions involving child protection systems. The same story can be lived, experienced and felt by each of those involved in a different way. Listening and gathering, qualitatively, the voice of the protagonists allows us to get closer to the reality of these families.

\section{Ethics}

The project 'Family reunification as a challenge of the child protection system: research, evaluation and implementation of a socio-educational programme' from which the present study is based was presented to and approved by the Commission of Bioethics of the University of Barcelona (IRB00003099).

\section{Funding}

The authors disclosed receipt of the following financial support for the research, authorship, and/or publication of this article: This study was developed by the research group GRISIJ (Research Group for Social and Educational Interventions in Child and Youth) (2017SGR905) and it was financed by the Ministry of Science, Innovation and Universities, the Spanish State Research Agency and the European Regional Development Fund (EDU2014-52921-C2) and (RTI2018-099305-B-C21).

\section{Acknowledgements}

We would like to thank all the families who carried out the 'Walking family' programme and all the parents and children who participated in the focus groups.

\section{References}

Arranz, E., Olabarrieta, F., Manzano, A., Barreto, F. B., Roncallo, C. P., Sánchez, M., Rekagorri, J., \& Garcia, M. D. (2019). Assessment and preventive education for families, based on the principles of positive parenting. Early Child Development and Care, 189(5), 792-801. https://doi.org/10.1080/03004430.2017.1344234

Balsells, M., Pastor, C., Amorós, P., Mateos, A., Ponce, C., \& Navajas, A. (2014). Child welfare and successful reunification through the socio-educative process: Training needs 
among biological families in Spain. Social Sciences, 3(4), 809-826. https://doi.org/10. 3390/socsci3040809

Balsells, M. À., Mateos, A., Urrea, A., \& Vaquero, E. (2018). Positive parenting support during family reunification. Early Child Development and Care, 188(11), 1567-1579. https://doi.org/10.1080/03004430.2018.1491559

Balsells, M. À ,Pastor, C., Amorós, P., Fuentes-Peláez, N., Molina, M. C., Mateos, A., Vaquero, E., Ponce, C., Mateo, M. I., Parra, B., Torralba, J. M., Mundet, A., Urrea, A., Ciurana, A., Navajas, A., \& Vázquez, N. (2015). Caminar en familia: Programa de competencias parentales durante el acogimiento y la reunificación familiar [Walking family. Programme of parental skills during foster care and reunification]. Ministerio de Sanidad, Servicios Sociales e Igualdad, Centro de Publicaciones. www.caminarenfa milia.udl.cat/

Balsells, M. À., Urrea, A., Ponce, C., Vaquero, E., \& Navajas, A. (2019). Claves de acción socioeducativa para promover la participación de las familias en procesos de acogimiento [Socio-educative key actions to promote family participation in foster care processes]. Educación XX1, 22(1), 401-423. https://doi.org/10.5944/educxx1.21501

Benbenishty, R., Davidson-Arad, B., López, M., Devaney, J., Spratt, T., Koopmans, C., Knorth, E., Witteman, C., Del Valle, J. F., \& Hayes, D. (2015). Decision making in child protection: An international comparative study on maltreatment substantiation, risk assessment and interventions recommendations, and the role of professionals' child welfare attitudes. Child Abuse \& Neglect, 49, 63-75. https://doi.org/10.1016/j.chiabu.2015. 03.015

Bernedo, I. M., Salas, M. D., Fuentes, M. J., \& García-Martín, M. Á. (2014). Foster children's behavior problems and impulsivity in the family and school context. Children and Youth Services Review, 42, 43-49. https://doi.org/10.1016/j.childyouth. 2014.03.022

Biehal, N. (2014). A sense of belonging: Meanings of family and home in long-term foster care. British Journal of Social Work, 44(4), 955-971. https://doi.org/10.1093/bjsw/bcs177

Cuenca, M. E., Campos, G., \& Goig, R. M. (2018). El tránsito a la vida adulta de los jóvenes en acogimiento residencial: El rol de la familia [Young people's transition from residential care to adulthood; the family's role]. Educación XX1, 21(1), 321-344. https:// doi.org/10.5944/educxx1.20201

Dakof, G. A., Cohen, J. B., Henderson, C. E., Duarte, E., Boustani, M., Blackburn, A., Venzer, E., \& Hawes, S. (2010). A randomized pilot study of the Engaging Moms Program for family drug court. Journal of Substance Abuse Treatment, 38(3), 263-274. https://doi.org/10.1016/j.jsat.2010.01.002

Delfabbro, P., Fernandez, E., McCormick, J., \& Kettler, L. (2013). Reunification in a complete entry cohort: A longitudinal study of children entering out-of-home care in Tasmania, Australia. Children and Youth Services Review, 35(9), 1592-1600. https://doi. org/10.1016/j.childyouth.2013.06.012

Ellingsen, I. T., Shemmings, D., \& Størksen, I. (2011). The concept of 'family' among Norwegian adolescents in long-term foster care. Child and Adolescent Social Work Journal, 28(4), 301-318. https://doi.org/10.1007/s10560-011-0234-0

Farmer, E. (2014). Improving reunification practice: Pathways home, progress and outcomes for children returning from care to their parents. British Journal of Social Work, 44(2), 348-366. https://doi.org/10.1093/bjsw/bcs093 
Farmer, E., \& Wijedasa, D. (2013). The reunification of looked after children with their parents: What contributes to return stability? British Journal of Social Work, 43(8), 1611-1629. https://doi.org/10.1093/bjsw/bcs066

Fuentes, M. J., Bernedo, I. M., Salas, M. D., \& García-Martín, M. A. (2018). What do foster families and social workers think about children's contact with birth parents? A focus group analysis. International Social Work, 62(5), 1416-1430. https://doi.org/ $10.1177 / 0020872818775475$

Gibbs, G. (2012). El análisis de datos cualitativos en investigación cualitativa [Analyzing qualitative data]. Ediciones Morata.

Goemans, A., Vanderfaeillie, J., Damen, H., Pijnenburg, H., \& Van Holen, F. (2016). Reunification of foster children: Factors associated with reunification outcomes in Flanders and the Netherlands. Children and Youth Services Review, 70, 284-292. https://doi.org/10.1016/j.childyouth.2016.09.023

Goodyer, A. (2014). Children's accounts of moving to a foster home. Child \& Family Social Work, 21(2), 188-197. https://doi.org/10.1111/cfs.12128

Hansen, P., \& Ainsworth, F. (2013). Australian child protection services: A game without end. International Journal of Social Welfare, 22(1), 104-110. https://doi.org/10.1111/j. 1468-2397.2011.00859.x

Kiraly, M., \& Humphreys, C. (2013). Perspectives from young people about family contact in kinship care: "Don't push us-listen more". Australian Social Work, 66(3), 314-327. https://doi.org/10.1080/0312407X.2012.715658

Landsman, M. J., Boel-Studt, S., \& Malone, K. (2014). Results from a family finding experiment. Children and Youth Services Review, 36, 62-69. https://doi.org/10.1016/j.ch ildyouth.2013.10.025

León, E., \& Palacios, J. (2004). Las visitas de los padres y la reunificación familiar tras el acogimiento [Parent visits and family reunification after foster care]. Portularia, 4, 241-248.

Lietz, C. A., \& Strength, M. (2011). Stories of successful reunification: A narrative study of family resilience in child welfare. Families in Society: The Journal of Contemporary Social Services, 92(2), 203-210. https://doi.org/10.1606/1044-3894.4102

Llosada-Gistau, J., Montserrat, C., \& Casas, F. (2017). Cómo influye el sistema de protección en el bienestar subjetivo de los adolescentes que acoge [How does the child protection system influence the subjective well-being of adolescents in care?]. Sociedad e Infancias, 1, 261-282. https://doi.org/10.5209/SOCI.55830

López, M., \& Del Valle, J. F. (2015). The waiting children: Pathways (and future) of children in long-term residential care. British Journal of Social Work, 45(2), 457-473. https:// doi.org/10.1093/bjsw/bct130

Maltais, C., Cyr, C., Parent, G., \& Pascuzzo, K. (2019). Identifying effective interventions for promoting parent engagement and family reunification for children in out-of-home care: A series of meta-analyses. Child Abuse \& Neglect, 88, 362-375. https://doi.org/10. 1016/j.chiabu.2018.12.009

Mateos, A., Vaquero, E., Balsells, M. A., \& Ponce, C. (2017). 'They didn't tell me anything; they just sent me home': Children's participation in the return home. Child \& Family Social Work, 22(2), 871-880. https://doi.org/10.1111/cfs.12307

Ministerio de Sanidad Consumo y Bienestar Social. (2018). Boletín de Datos Estadísticos de Medidas de Protección a la Infancia. Boletín 20. Datos 2017. Ministerio de Sanidad Consumo y Bienestar Social. https://observatoriodelainfancia.vpsocial.gob.es/estadisti cas/estadisticas/home.htm 
Murphy, D., \& Jenkinson, H. (2012). The mutual benefits of listening to young people in care, with a particular focus on grief and loss: An irish foster carer's perspective. Child Care in Practice, 18(3), 243-253. https://doi.org/10.1080/13575279.2012.683772

Nybell, L. M. (2013). Locating "youth voice": Considering the contexts of speaking in foster care. Children and Youth Services Review, 35(8), 1227-1235. https://doi.org/10.1016/j.ch ildyouth.2013.04.009

Osterling, K. L., \& Han, M. (2011). Reunification outcomes among Mexican immigrant families in the child welfare system. Children and Youth Services Review, 33(9), 1658-1666. https://doi.org/10.1016/j.childyouth.2011.04.020

Potgieter, A., \& Hoosain, S. (2018). Parents' experiences of family reunification services. Social Work, 54(4), 436-451. https://doi.org/10.15270/54-4-671

Rodrigo, M. J. (2010). Promoting positive parenting in Europe: New challenges for the European society for developmental psychology. European Journal of Developmental Psychology, 7(3), 281-294. https://doi.org/10.1080/17405621003780200

Rodrigo, M. J. (2016). Quality of implementation in evidence-based positive parenting programs in Spain: Introduction to the special issue. Psychosocial Intervention, 25(2), 63-68. https://doi.org/10.1016/j.psi.2016.02.004

Rodrigo, M. J., Amorós, P., Arranz, E., Hidalgo, M. V., Máiquez, M. L., Martín, J. C., Martínez, R.A., \& Ochaita, E. (2015). Guía de buenas prácticas en parentalidad positiva. Un recurso para apoyar la práctica profesional con familias [Good Practice Guide on positive parenting. A resource to support professional practice with families.]. Ministerio de Sanidad, Política Social e Igualdad. www.mscbs.gob.es/ssi/ familiasInfancia/ayudas/docs2013-14/GuiadeBuenasPracticas2015.pdf

Thoburn, J., Robinson, J., \& Anderson, B. (2012). Returning children home from public care. Social Care Institute for Excellence.

Thomas, M., Chenot, D., \& Reifel, B. (2005). A resilience-based model of reunification and reentry: Implications for out-of-home care services. Families in Society: The Journal of Contemporary Social Services, 86(2), 235-243. https://doi.org/10.1606/1044-3894.2458

Turcotte, D., \& Hélie, S. (2012). Child protection policy reform in Quebec: Its impact on placement and stability in substitute care. Child Welfare, 91(6), 125-148.

Wilkins, M., \& Farmer, E. (2015). Reunification. An evidence-informed framework for return home practice. National Society for the Prevention of Cruelty to Children. 